\title{
Nestosanos en Guadalajara. Triunfo y decadencia de un grupo privilegiado, 1780-1836
}

\author{
por \\ Jesús Ruiz de Gordejuela Urquijo ${ }^{1}$ \\ Universidad Rey Juan Carlos
}

Este artículo pretende mostrar cómo los naturales de Lanestosa (Vizcaya) durante el último cuarto del siglo XVIII fueron capaces de crear una importante red de paisanaje en la ciudad novohispana de Guadalajara, hasta convertirse en un grupo privilegiado que alcanzó el éxito económico y social, personificado en la figura de Juan Manuel Caballero. La inestabilidad que conllevó la Insurgencia debilitó su papel protagónico, por lo que muchos nestosanos decidieron regresar a la península con la intención de reemprender sus vidas. Para ello, nos hemos servido de la correspondencia inédita del comerciante asentado en Cádiz Francisco de Carranza, y que además nos ha permitido descubrir aspectos inéditos de la vida de Francisco Martínez Negrete antes de que se convirtiera en uno de los hombres más relevantes del noroccidente mexicano decimonónico.

Palabras Clave: emigración; vascos; Lanestosa; México; Juan Manuel Caballero; Francisco Martínez Negrete; expulsión de españoles.

Cómo CITAR este artículo / Citation: Ruiz de Gordejuela Urquijo, Jesús, "Nestosanos en Guadalajara. Triunfo y decadencia de un grupo privilegiado, 1780-1836", Revista de Indias, LXXX/280 (Madrid, 2020): 751-779. https://doi.org/10.3989/revindias.2020.021.

Lanestosa es una villa situada en el valle del río Calera fundada en 1287 para asegurar el importante comercio entre la meseta castellana y el mar cantábrico. Pertenece a la comarca de las Encartaciones en el Señorío de Vizcaya y está prácticamente incrustado entre el valle de Soba (Montañas de Santander) y el valle de Carranza con una extensión de $1,31 \mathrm{~km}^{2}$ lo que le confiere como uno de los ayuntamientos más pequeños de España. Desde su

1 jesus@ruizdegordejuela.com, ORCID iD: https://orcid.org/0000-0002-7016-6837 
origen esta población mantuvo su carácter de paso continuo de mercancías y personas lo que fue marcando el carácter de los nestosanos, que es como se denomina a los naturales de esa localidad. Su modus vivendi durante el periodo que abarca este estudio se basaba principalmente en la producción agrícola (maíz, patatas y alubias) y ganadera (vacas y caballos), nada distinto al resto de las poblaciones de la franja cantábrica, pero lo que sí les diferenciaba era su profunda implicación en el comercio y no solo por el que se realizaba en el lugar (nueve tiendas de lienzos y comestibles) ${ }^{2}$ sino porque fue cuna de numerosos comerciantes repartidos por las principales plazas mercantiles de la península y de la América española a lo largo de los siglos XVIII y XIX.

En 1802 el Diccionario geográfico-histórico de España señalaba que en Lanestosa «su contribución es al respecto de 24 hogueras, y su población de 402 almas», las mismas que tenía 24 años después ${ }^{3}$. La información sobre las características de esta localidad es más explícita en un documento de 1799 en el que hace referencia al colindante valle de Carranza, y que sin duda es válido para la villa de Lanestosa y sus gentes. El texto decía que en estos valles vizcaínos era difícil encontrar hombre o mujer que al menos no supieran leer y «los más saben escribir, cuidando del mismo modo con el mayor tesón y vigilancia de que sus hijos e hijas aprendan» como parte de la estrategia familiar por ofrecer una salida profesional a sus vástagos que desde bien jóvenes debían abandonar sus hogares para viajar a «la Corte y demás provincias del reino y de ambas Américas en que se dedican al comercio y a las ciencias han hecho y hacen grandes fortunas, de las cuales disfruta su propio país gran parte» ${ }^{4}$.

Una de las facetas benefactoras en las que destacaron los vascos fue la fundación en sus pueblos natales de escuelas de primera enseñanza y becas de estudios para sus coterráneos, tanto niños como niñas; y los nestosanos radicados en Guadalajara también cumplieron con esta tradición. Cuando en 1775 José Bringas de la Peña donó 110.000 rs. y una renta de 250 ducados al año para este fin, determinó, con claro carácter laico, que fueran sus patronos el concejo y los vecinos de la villa. En 1806 se construyó una escuela de nueva planta, pero en esta ocasión fue otro paisano avecindado en la misma ciudad novohispana, Juan Ángel Ortiz de Rozas, quien se haría cargo de su

2 Madoz, 1848-50. En esa fecha el municipio contaba con 233 almas. Prácticamente la población se ha mantenido igual, de hecho, en 2017 el número de habitantes es de 266. (Instituto Nacional de Estadística).

3 Idem.

${ }^{4}$ Labayru, 1885: 519. Apuntes para la crónica de la villa de Lanestosa en el Señorío de Vizcaya. (copia fiel de un documento de 1792). 
coste. El Ayuntamiento recordaba a todos sus vecinos que, de forma gratuita, acudieran con sus bueyes o bien aportaran algún dinero para terminar la escuela «por redundar en beneficio de todos». Para finalizar con estas donaciones debemos recordar así mismo a Juan Manuel Caballero, quien dispuso que a su muerte se creara una fundación de doce becas, de cinco mil reales cada una, para que los parientes pobres pudieran estudiar carrera eclesiástica o militar en primero y preferente lugar, y si esto no fuese su opción principal, se dedicasen a cualquier ciencia o arte liberal. El capital de la referida fundación se constituyó con la aportación de 70.000 pesos (20.000 procedentes de su difunta esposa Juana de Dios Fernández de Barrena y resto aportado por el referido Caballero) $)^{5}$.

Otra circunstancia que facilitó que los jóvenes nestosanos pudieran conformar parte de estos emigrantes privilegiados fue su condición de hidalgo universal. Gracias al menos a estas prerrogativas, los vascos pudieron acceder a cargos y empleos a lo largo y ancho de los territorios españoles. Así, orgullosos de esta nobleza la harán valer ante la sociedad americana, lo que les servirá para abrir las puertas de ventajosos matrimonios. Pero antes, los decididos a emigrar debían obtener el expediente de hidalguía, en el que no solo se hacía constar su condición de vizcaíno originario, sino que también se reflejaban los cargos públicos que habían ostentado sus antepasados, y todo ello para dar más «brillo» a su condición. A modo de ejemplo, podemos señalar a los hermanos Juan Ángel y Juan Francisco Ortiz de Rozas Escudero, nacidos en Lanestosa, quienes solicitaron en la Chancillería de Valladolid su expediente de limpieza de sangre e hidalguía desde Guadalajara a mediados del siglo XVIII. Gaspar Caballero y Bárcenas, padre de Juan Manuel Caballero, fue reconocida su condición de hidalgo y noble en 1754, y en 1816 en vísperas de viajar a México, Francisco Martínez Negrete ${ }^{6}$ también obtuvo su

5 López Gil, 1975. Testamento de 27 de noviembre de 1835, otorgado en Guadalajara ante el notario Joaquín María de Robles.

6 Acta notarial de limpieza de sangre, p. 110 a 120. Notario Josef Fernández de la Colina. El 30 de julio de 1816 Francisco Martínez Negrete presenta información de su nobleza y limpieza de sangre por lo que presentó a tres testigos que lo confirmasen. Archivo Histórico Provincial de Vizcaya.

Nació en Lanestosa el 18 de febrero de 1796. Fue bautizado con el nombre de Francisco Julián Gabriel y era hijo de Matías Martínez Negrete y María Ortiz de Rozas y Cano. La importancia de este personaje en la historia del noroccidente mexicano se ha visto reflejado en numerosos estudios que han investigado a este importante hombre de negocios del México decimonónico desde que tenía 39 años hasta su muerte en 1874, pero por desgracia se desconoce sus años anteriores y creemos que con este trabajo se aporta información significativa de su vida en este periodo hasta ahora desconocido. 
expediente. En este documento se percibe la importancia del estatus social de la familia al hacer relación de los méritos alcanzados por sus antepasados más cercanos. Así se puede leer que su padre Matías ocupó los cargos de alcalde, regidor y síndico procurador general de la villa de Lanestosa «los que solo se confieren a los caballeros Nobles hijosdalgo notorios y que bien sabe que sus ascendientes los obtuvieron igualmente» por lo que como hijo del Señorío de Vizcaya «gozan y han gozado de las franquezas exenciones e inmunidades que deben disfrutar y disfrutan los caballeros escuderos y los que son de tal calidad y nobleza y cristiandad en cuya posesión y goce han estado y están». Pero no solo su padre ostentó cargos de responsabilidad, su tío de igual nombre, Francisco Martínez Negrete, en 1818 era director de los cinco Gremios de Madrid y Factor de las Reales Provisiones del Ejército y Principado de Cataluña, mientras que sus otros tíos, Simón y Antolín, residían en ciudad de México al despuntar el siglo?.

La relación entre familiares y parientes sería otro pilar fundamental para proporcionar a los que iban a emigrar el anhelado ascenso social y económico, y no solo como individuos sino como miembros de unas familias a las que se deben.

Por tanto, la idea de que los vascos emigraron durante siglos como causa efecto de la pobreza de sus recursos productivos no es del todo exacta. Es cierto que una sobrepoblación incapaz de subsistir en una economía de montaña obligaba a apostar por un futuro en otros destinos, aunque por desgracia no todos podían hacerlo. Aunque todos los vizcaínos eran nobles por su condición de hidalgos universales, esto no significa que todos fueran iguales, ni en recursos económicos ni en importancia social. Así surge la idea de que no emigra quien quiere sino quien puede. Como ha quedado totalmente esclarecido la emigración en cadena no era apta para todos los jóvenes con ansia de hacer carrera. En resumen, primero debían demostrar ciertas habilidades mercantiles, además de tener parientes que los reclamasen y, no menos importante, capital suficiente para afrontar el largo viaje.

\section{Nestosanos en Guadalajara: El tRIUNFO DE UN GRUPO PRIVILEGIADO}

La presencia vasca en la Nueva España y en especial en el noroccidente mexicano es conocida ya desde los primeros años de la historia del virreinato ${ }^{8}$. Durante los siglos XVII y XVIII los vascos y navarros además de des-

\footnotetext{
7 Archivo Foral de Bizkaia. JCR 4555/006 Lanestosa, 4 de agosto de 1818.

8 Olveda Legaspi, 1996: 58-64.
} 
empeñar importantes cargos y empleos de la administración virreinal llegaron a dominar el comercio tanto exterior como al menudeo. Con la llegada de familiares y paisanos se desarrolló una tupida red comercial y de relaciones en la que supieron mantener su peculiaridad cultural sin olvidar su profunda lealtad a la corona. Por si esto no fuera suficiente, las reformas borbónicas del último tercio del siglo XVIII impulsaron aún más la emigración vasca a México, siendo las Encartaciones de Vizcaya y el valle alavés de Ayala los que con más jóvenes contribuyeron a hacer la carrera en esas tierras. Asimismo, los naturales de las Montañas de Santander participaron de modo destacado en esta emigración, por lo que los nestosanos no solo se relacionaron con el resto de sus paisanos, sino que, también lo hicieron con sus vecinos del valle de Soba.

Aunque hay que ser cautos cuando se ofrecen cifras de la población española en la Nueva España (tanto europea como americana) su número no alcanzaría los 14.000 individuos durante las últimas décadas del siglo XVIII, distribuidos de modo irregular a lo largo y ancho del virreinato, con un $25 \%$ en la capital, mientras que el resto residiría en las principales ciudades de la colonia. En Guadalajara que contaba en este periodo con una población cercana a los 25.000 habitantes $^{9}$, el número de españoles ascendía a los 1.994 individuos siendo tan solo 169 los españoles europeos, de los cuales 55 eran nacidos en el País Vasco y Navarra y 32 procedentes de Santander ${ }^{10}$. La mayor parte de los vascos residían en el centro de la ciudad, sobre todo en los dos cuarteles del sur, y más en concreto en la calle San Francisco, en cuyos portales se localizaban los principales comercios de la ciudad.

Durante las dos últimas décadas del siglo XVIII, los vascos monopolizaron casi todos los altos cargos de gobierno y junto a sus vecinos los montañeses dominaron el comercio tapatío, al modo de cómo lo ejercían en el consulado de comerciantes de ciudad de México. Como dice Brading, para este periodo tardocolonial la élite económica y política eran prácticamente las mismas ya que «la posesión de un cargo de funcionario seguía de cerca a la distribución de la riqueza ${ }^{11}$.

Aunque compartimos con John E. Kicza ${ }^{12}$ que la identidad familiar y su deber hacia ella determinaba, más que ningún otro factor, el lugar que ocupaba un individuo en la sociedad, no debemos olvidar que para los vascos su pertenencia a un grupo étnico distinto y diferenciado en prerrogativas marca-

\footnotetext{
9 Olveda Legaspi, 1991.

10 Castañeda, 1998: 171.

11 Brading, 1975: 403.

12 Kicza, 1991.
} 
ba su vida pública y privada ${ }^{13}$. Los vascos ya asentados preferían a la hora de casar a sus hijas criollas hacerlo con peninsulares y dentro de estos, preferentemente con los de su mismo origen regional. Pero estas circunstancias no deben entenderse como elementos excluyentes, sino preferibles, por lo que también era habitual que los pretendientes europeos esposaran con criollas no vascas y que compartieran negocios con otros españoles y criollos. No cabe duda de que muchos de los jóvenes llegados al virreinato estaban más dispuestos a llevar una vida sacrificada en pos de alcanzar riqueza y ascenso social, lo que les hacía más adecuados para esposar a sus hijas y asegurar el futuro de sus negocios ${ }^{14}$.

Aunque resulta difícil conocer con precisión, quién fue el primer nestosano que se asentó en la Nueva Galicia (tras las Reformas Borbónicas se denominará Intendencia de Guadalajara), podemos confirmar que el primero en destacar fue Juan Francisco Ortiz de Rozas Escudero quien en 1753 era tesorero y oficial de la Real Hacienda en los Álamos (Sonora). Este reclamó años más tarde a su hermano Juan Ángel, (Lanestosa, 1740) y que en 1778 llegaría a ser alcalde de Guadalajara y uno de los promotores de la creación del Consulado de comerciantes. A partir de este último llegarían bajo su tutela otros jóvenes coterráneos que desempeñarían un papel determinante en la consolidación de una red familiar y de paisanaje ${ }^{15}$.

Los hermanos Ortiz de Rozas reclamaron a sus sobrinos Francisco del Cerro, Manuel Francisco Urrutia y a su primo Juan Manuel Escudero Colina quienes se embarcaron rumbo a Veracruz en 1787 en la fragata El Mentor ${ }^{16}$. Este último a su vez hizo lo mismo poco tiempo después con su hermano Miguel Gaspar (quien será miembro del Ayuntamiento de Guadalajara en 1806 y 1807). En el noroccidente novohispano otros nestosanos también lucharon por hacerse un hueco en la elitista sociedad de la Nueva España, como Luis Domingo Ruiz Bringas quien en 1786 junto a José Sebastián Bringas Alonso de Lajarrota residían en el Real del Rosario (Sinaloa).

Aunque es cierto que estos vizcaínos destacaron en la carrera comercial, no debemos olvidar que también la carrera administrativa ofrecía la posibilidad del tan anhelado ascenso. Ejemplo de esto último son sus paisanos Juan

13 Brading, 1975. Sobre este asunto este autor ya escribió que «los vascos tenían una alta conciencia provinciana; su partido dentro del Consulado tenía por base la organización comunal, consistente en la cofradía, su sociedad económica, las asociaciones mercantiles y el compadrazgo».

14 Kizca, 1986: 169-170.

15 Archivo General de Indias (AGI). Contratación, 5526, №.1, R.29., (17 de julio de 1783).

16 AGI. Contratación, 5531, N.1, R.32. 
Ortiz de Rozas y Cano (tío de Francisco Martínez Negrete) y Luis Ruiz y Bringas que fueron contadores de las Reales Cajas de la Intendencia y Provincia de Guadalajara en 1792.

Durante este periodo finisecular encontramos a otros naturales de Lanestosa como Manuel del Castillo Negrete, quien fuera oidor de la Audiencia de Guadalajara en 1790 y posteriormente en 1810 ministro de Indias y José Sebastián Ruiz Bringas quien fue cajero de otro rico comerciante, el vasco Andrés Arzamendi.

Sin embargo, no todos los jóvenes procedentes de esta villa vizcaína se dirigieron a esta capital tapatía, sino que también se asentaron en las principales plazas comerciales del virreinato, en donde además de gestionar sus propios negocios fueron corresponsales de sus paisanos a lo largo de toda la Nueva España ${ }^{17}$. Entre estos últimos podemos señalar a José de la Lama y Gutiérrez (sobrino de Juan Manuel Caballero) aunque en su licencia de embarque consta que se dirigía a casa de su primo Juan Ortiz de Guadalajara finalmente se colocó como factor y director de la casa de comercio de Juan de la Peña Madrazo en 1795, antes de fundar su propio comercio y ejercer de socio y corresponsal de muchos comerciantes vascos en Veracruz. Otros nestosanos más, como sus hermanos Juan y Francisco, Antonio Gómez Caballero (n. 1783, sobrino de Juan Manuel Caballero), Julián Ruiz y Gutiérrez, Andrés Pérez Ruiz y Manuel Gutiérrez y Ruiz crearán sus propios comercios en Veracruz y ciudad de México.

Pero no debemos obviar la importancia de sus coterráneos en España, principalmente en Cádiz en donde se encontraba el comerciante Francisco de Carranza. Gracias a las numerosas cartas que mantuvo con sus paisanos en la Nueva España y en la península hemos podido conocer mejor a este grupo privilegiado desde 1816 a 1836. En Madrid se encontraba otro paisano, Miguel Ortiz de Rosas Escudero'8, quien defendió los intereses de los comerciantes tapatíos en la creación del consulado de comerciantes de Guadalajara en 1795 .

Muchos de los citados fallecieron alrededor del cambio de siglo sin sufrir los avatares que sacudirían a la sociedad novohispana a lo largo de las siguientes décadas. Los que podríamos llamar como segunda generación de emigrados procedentes de Lanestosa, es decir los llegados a partir de las últimas décadas del siglo hasta el inicio de la insurgencia en 1810, padecerán entre muchas vicisitudes, la crisis de un imperio en descomposición, la falta

17 Labayru, 1885: 519. Apuntes para la crónica de la villa de Lanestosa en el Señorío de Vizcaya. (copia fiel de un documento de 1792).

18 Este había emigrado años antes con sus hermanos Juan y Francisco a Guadalajara. 
de numerario con la convalidación de los vales reales, la guerra de Independencia en la península y sobre todo el proceso independentista. A pesar de estos problemas, los nestosanos se consolidaron como grupo privilegiado de la sociedad y economía tapatía. Dos de los jóvenes que viajaron en el buque El Mentor, Juan Manuel Caballero y Francisco del Cerro, alcanzaron el soñado triunfo. Ambos se casaron con ricas herederas, sus negocios fueron exitosos y ocuparon distintos cargos en el ayuntamiento tapatío. Cerro se esposó con Isabel Ortiz Sierra, hija de su patrón Juan Ángel Ortiz, lo que le facilitó un rápido ascenso social y la disposición de un importante capital para ocuparse de negocios de más envergadura. Durante los años 1802 y 1810 desempeñó distintos cargos en el consulado y en el ayuntamiento, y el volumen de mercancías que negoció en ciudades y reales de minas como de Acaponeta, Cosalá o Pánuco, entre 1800 y 1820, varió entre los 10.000 y 17.000 pesos anuales en productos procedentes de Europa (efectos de abarrote, de pulquería, acero vizcaíno, telas y licores, entre otros).

Especial atención debemos prestar a Juan Manuel Caballero; primero porque llegó a ser uno de los hombres más ricos de la Intendencia de Guadalajara; segundo, por ser un ejemplo de padecimientos que sufrieron los españoles europeos durante la Insurgencia en Guadalajara y finalmente por su estrecha relación con Francisco Martínez Negrete, personaje este último que pretendemos mostrar con más detenimiento y que representará la tercera partida de nestosanos, es decir los llegados a estas tierras novogalaicas durante la guerra de independencia mexicana.

Juan Manuel Caballero es, a día de hoy, un personaje conocido en Guadalajara, gracias en parte a que una de las principales calles de esta ciudad lleva su nombre, y a su vez porque aún es recordado como uno de los más grandes benefactores de esta capital. Cuando Caballero llegó a Guadalajara procedente de su villa de Lanestosa en 1787 fue colocado en la casa comercial de otro vasco, el alavés Ramón Fernández Barrena, rico comerciante procedente de la localidad de Santa Cruz de Campezo, (lugar a escasos $20 \mathrm{~km}$ de Espronceda, Navarra, que es en donde nació su amigo el obispo de la diócesis neogallega Juan Cruz Ruiz de Cabañas). Era tal la confianza en su joven cajero que en su testamento realizado en 1798 aparece como uno de los tres albaceas. A partir de esta fecha la carrera comercial y política de Caballero sentirá un importante impulso. Un año después fue nombrado teniente de síndico en el Consulado de Guadalajara, cargo que repetirá en distintas ocasiones. En 1802 fallece su patrón y socio, y catorce meses después Caballero - con 47 años - contrajo matrimonio con una de sus hijas y heredera, Juana de Dios Barrena Vizcarra. En este ínterin, se hizo cargo en exclusiva de la testamentaría de su suegro y junto a este enorme legado se le sumó la parte 
de los bienes inmuebles que correspondía a la otra heredera, su cuñada María Manuela (novicia en el convento de Santa Mónica) quien delegó en primera instancia en su hermana para que fuera gestionado por Caballero por un valor de 282.280 pesos $^{19}$. Finalmente, en octubre de 1803, su esposa le nombró en su testamento heredero universal. Su fortuna procedente de su padre y de su abuelo materno, el primer marqués de Pánuco, ascendía a 643.804 pesos. Pero no solo disponía de estos bienes, además era propietario de numerosos negocios como la tienda que poseía en el portal del Convento de Santa María de Gracia $^{20}$ en donde vendía al menudeo las múltiples mercancías inglesas procedente de Jamaica que desembarcaban en el puerto de San Blas (muchas de estas adquiridas por contrabando).

A partir de este momento y tal como nos lo indica Jaime Olveda, su proyección mercantil creció de modo singular hasta convertirse en uno de los hombres más acaudalados de la Intendencia de Guadalajara. Para gestionar sus negocios en Veracruz y en la ciudad de México contó con la ayuda de sus sobrinos José y Juan Manuel de la Lama, ambos también nacidos en Lanestosa.

A pesar de la profunda inestabilidad política que marcó la primera década del siglo XIX (guerra contra Inglaterra, el azote del corso, la crisis monárquica española y la desastrosa guerra de independencia contra la Francia napoleónica) los jóvenes nestosanos no cejaron en buscar el modo de arribar a tierras novohispanas. Durante este periodo llegaron los hermanos citados Lama Caballero. José (nacido en 1773), Manuel Ascensio (n. 1780), Miguel (n. 1790) y Cipriano José (n. 1794), (este último falleció prematuramente en 1813 en la capital virreinal). Es interesante señalar que el padre de estos hermanos, José Manuel de la Lama y Rozas también emigró a la Nueva España asentándose en la villa del Parral (Sonora) donde su hermano Francisco tenía una tienda.

A principios de siglo Francisco Ortiz Gómez llegó a Pánuco en donde se hizo cargo de la administración las minas que allí se encontraban. En 1807 recibió un poder para la negociación de estas explotaciones con el fin de que vendiera todas las posesiones que quedaron después de la muerte de su propietario el marqués de Pánuco. Un año antes, la negociación había recaído en los esposos de las herederas de las minas, Juan Manuel Caballero y el alavés Juan Francisco Corcuera. Es evidente la confianza del primero con su condiscípulo Francisco Ortiz quien delegó tan importante tarea.

En 1804, varios jóvenes nestosanos encabezados por Manuel García Sainz pasaron a Guadalajara; el primero para ayudar a su tío Miguel Ortiz Gómez (este último había hecho lo propio tres años antes cuando se instaló en la casa

\footnotetext{
19 Olveda Legaspi, 2003: 196-197.

20 Lancaster-Jones, 1952: 658.
} 
y giro de su tío Julián Ortiz), Manuel García Sainz, quien fue reclamado por su tío, el comerciante tapatío Manuel García Ranero y Valerio Ortiz quien se dirigió a San Miguel de Horcasitas (Sonora) en donde le esperaba su tío el también nestosano Fernando Iñigo Ruiz ${ }^{21}$. Asimismo, otro paisano, Joaquín Gómez de Rozas Velasco viajó hasta Veracruz en donde su tío Manuel Velasco le aguardaba para promocionarle en la carrera comercial.

El 26 de diciembre de 1804 se aprobó la Real Cédula de Consolidación por la que se procedía la enajenación y venta de bienes raíces pertenecientes a obras pías. Esta medida provocó una grave crisis económica en la Nueva España, al verse privados los comerciantes, mineros y hacendados, de los capitales que la Iglesia prestaba para poder realizar sus negocios. Pero no solo esta desgraciada disposición hizo cada vez más difícil los negocios de los españoles en el virreinato, durante los años previos a la independencia, los elevados impuestos, aranceles, la cada vez mayor relevancia del contrabando y la raquítica red viaria infestada de ladrones, hizo del comercio un ejercicio de mucha incertidumbre. Aunque este contexto restringió la llegada de los naturales de Lanestosa, como del resto de peninsulares, a tierras novohispanas en ningún modo anuló las expectativas que habían depositado las familias en que sus hijos hicieran carrera comercial en compañía de sus familiares y paisanos. Por desgracia, ni su condición de español ni su posición privilegiada en un entorno protegido les aseguraba el éxito 22 .

\section{LA INSURGENCIA Y EL PRINCIPIO DEL FIN NESTOSANO}

Todo cambió en el virreinato cuando el 16 de septiembre de 1810 el párroco de la localidad de Dolores, Miguel Hidalgo, llamó a sus vecinos a sumarse a la lucha en contra del mal gobierno. En este momento nació el movimiento insurgente, que afectará a toda la Nueva España y a todos sus habitantes, hasta que en 1821 México alcanzó la independencia. Aunque la guerra afectó por poco tiempo a la ciudad de Guadalajara (septiembre de 1810 a enero de 1811), esta supuso una profunda fractura en la convivencia entre los españoles peninsulares y gran parte de los mexicanos.

Caballero, como el resto de los españoles europeos allí residentes, vivió en primera persona el antigachupismo que azotó a toda la geografía mexicana. Ante el terror que suscitaban las hordas insurgentes, el 10 de octubre el obis-

\footnotetext{
21 AGI. Indiferente General, 2135, N.10, 4 de mayo de1804.

22 Ruiz de Gordejuela Urquijo, 2011a. En esta obra se puede observar las enormes dificultades para subsistir que padecieron los vascos en tierras mexicanas.
} 
po Ruiz Cabañas junto a 200 españoles que le acompañaban abandonó Guadalajara rumbo al puerto de San Blas. El 27 de noviembre, Hidalgo tras llegar la capital tapatía ordenó el apresamiento de todos los españoles peninsulares y la incautación de sus bienes. La fama de Caballero como hombre honrado, generoso y totalmente adaptado a la vida novohispana le salvó la vida, suerte que no tuvieron una cifra no determinada de españoles que fueron asesinados. Viudo desde 1811, además de ocupar los cargos más elevados en el consulado y ayuntamiento fue asimismo elegido diputado electo a las Cortes de Cádiz en $1821^{23}$. Su prestigio era tal que se convirtió en un referente obligado para todos sus paisanos que querían medrar en los negocios en esa región mexicana.

Francisco Carranza encabezaba una misiva en la que se dirigía a Caballero como «Paisano, pariente, amigo y Señor». Su condición de coterráneo era tan importante como la de pariente, lo que nos confirma la importancia que otorgaban a esta circunstancia. El primer párrafo es aclaratorio para refrendar lo anterior al escribir «estar impuesto mucho tiempo ha, por las relaciones con los nestosanos en todas esa América, del establecimiento de vm. en esa ciudad muy circunstanciado». Carranza, como interlocutor de sus paisanos en Cádiz, fue solicitado para que ayudase a unos comerciantes en una expedición que se dirigía a Guadalajara, por lo que le instan a que «contribuyan en cuanto esté de su parte a que logren dichos Amigos felicidad en la empresa, a la que quedaré muy agradecido, como nestosano» ${ }^{24}$. Asimismo, la posibilidad de trabajar a las órdenes de Caballero resultaba muy atractiva al pagar muy bien a sus cajeros, tal y como cobraban sus paisanos Felipe Murua y José Gutiérrez con salarios anuales de $300 \operatorname{pesos}^{25}$.

Durante los años en que el virreinato sufrió la embestida insurgente, los españoles y en especial los comerciantes, fueron culpados por la propaganda independentista de los graves problemas que sufría la nación, responsables de atesorar y repatriar importantes capitales, imprescindibles para activar la de-

23 Ibarra, 2003: 151.

${ }^{24}$ Carta de Francisco de Carranza a Juan Manuel Caballero, Cádiz, 30 de mayo de 1816. Fondo privado del comerciante nestosano Francisco Carranza asentado en Cádiz entre 1808 y 1845 .

Fondo Francisco de Carranza, en adelante FFC. Debemos agradecer la gentileza del director de la página web Historias de Lanestosa, Ángel Manuel de la Cruz, quien nos facilitó el acceso y consulta de tan importante fondo privado (todavía no es de acceso libre) y que permanece sin catalogar profesionalmente. Nos hemos servido de los copiadores de cartas del citado comerciante Francisco de Carranza.

25 Carta de Francisco de Carranza a Francisco Ranero (del comercio de Madrid), Cádiz, 30 de mayo de 1820, FFC. 
ficitaria economía mexicana. Como debemos obviar que en la península se libraba una desoladora guerra contra el invasor francés, por lo que el flujo migratorio se redujo drásticamente. Así podemos leer en otra carta de Francisco de Carranza, quien solía auxiliar a sus paisanos cuando viajaban a América, que ya no eran bien recibidos los jóvenes emigrantes en México, tal y como le había sucedido cuando embarcó a Antonio Gómez para Veracruz, «sabe que allí no los llaman porque no los quieren...aún no he tenido contestación en virtud no dispondré de ningún joven mientras sus parientes de América no lo soliciten; pues no quiero verme reconvenido» ${ }^{26}$.

Tras la derrota de las tropas napoleónicas, y libre los mares para navegar sin riesgo a ser apresado por buques franceses, se dio la paradoja de que mientras en el virreinato los comerciantes españoles embarcaban con sus remesas para regresar definitivamente a España en previsión de que la revolución pudiera despojarlos de todos sus bienes, los jóvenes nestosanos se disponían a emigrar como lo habían hecho antes sus familiares y paisanos.

Al menos hubo varios contingentes de emigrantes procedentes de Lanestosa entre los años 1817 y 1821 . De los primeros en llegar a la intendencia de Guadalajara fue Francisco Martínez Negrete Ortiz (sobrino del general Pedro Celestino Negrete ${ }^{27}$ y al año siguiente lo hizo Manuel Sainz de la Lastra $^{28}$, quien tras viajar en el buque Fama desembarcó en el puerto de Veracruz. Este mismo año llegaba a este puerto jarocho, otro paisano, Bernardo Gutiérrez y Bringas $^{29}$, reclamado por su tío José de la Lama, vecino y del comercio de esta ciudad. Desconocemos si viajaron juntos o lo hicieron por separado, aunque la primera hipótesis es más verosímil ya que era costumbre que varios jóvenes viajaran juntos para auxiliarse durante el camino.

En 1820 Miguel Pedro Murua Escorza ${ }^{30}$ (Lanestosa, 1805-Carranza, 1870) llegaba a estas tierras del noroccidente después de permanecer el año anterior en casa de Francisco Fernández de la Colina del comercio de Madrid mientras esperaba fuera aprobada su licencia de embarque. En la misma embarcación, El Ramoncito, llegaban otros tres jóvenes destinados al comercio del nestosano José

26 Carta de Francisco de Carranza a Francisco Miguel Ranero (del comercio de Madrid), Cádiz, 18 de septiembre de 1818, FFC.

27 Lizama Silva, 2003: 171-187. Lizama Silva, 2013.

28 El pasaje fue pagado por su tío Francisco Fernández de la Colina de Madrid y su coste ascendió a 1.891 reales y 8 quintos.

29 Solicitud de licencia de embarque, (1817-09-26), AGI, Indiferente, 2142, N.71. Nació el 27 de diciembre de 1798. Hijo de Severino Antonio Gutiérrez y de María Bringas y Lama.

30 Se casó con María Josefa Encarnación Roncal Batíz (n. 1807) hermana de Trinidad, esta última contraerá matrimonio con el citado Martínez Negrete convirtiéndose por tanto en cuñados. 
Ortiz en Veracruz. Pero algo había cambiado en el proceso migratorio, ahora muchos jóvenes se embarcaban en la aventura americana sin tener un trabajo que le aguardase. En la siguiente carta de Carranza hacía referencia al joven citado Miguel Pedro Murua de la siguiente manera: «Es un joven de bella índole, advertido y de disposición para trabajar con provecho al lado de un hombre que sepa apreciar las buenas cualidades que lo caracterizan ${ }^{31}$. A su vez, José Felipe Gutiérrez Gutiérrez (Lanestosa, 1799) llegó a Guadalajara el 24 de marzo de 1819 a «casa de D. Juan Manuel Caballero; hasta la hora presente sin destino alguno porque este ya no tiene giro aunque estoy en su compañía». En la capital tapatía se encontró con «D. Francisco Ortiz y otros varios nestosanos $)^{32}$, que también se hallaban en casa de Caballero, en donde se alojaba cuando los negocios le obligaban a viajar a Guadalajara. En la travesía también viajaron los encartados Simón de Llano Capetillo, natural de Sopuerta, quien pasó a casa de su tío Manuel de Capetillo en la Hacienda de Cuisillos (Valle de Tala, Intendencia de Guadalajara), y Francisco Ranero y Rufino Helguero quienes hicieron su entrada en Guadalajara el 25 de agosto de $1820^{33}$. Tan solo cuatro años después de la llegada a México de Francisco Martínez Negrete, este reclamó a su sobrino Justo de Peñarredonda y Ortiz para que le auxiliase en su comercio de Durango ${ }^{34}$. El número de naturales de Lanestosa era tan importante que hasta el mismo alcalde de esta villa creía que en Guadalajara «a donde hay tanto nestosano y que estos son los dueños de aquella ciudad» ${ }^{35}$.

Tanto los recién llegados como los que aún permanecían en México pronto comprobaron que, tras la independencia, la sociedad mexicana anhelaba desaparecer todo vestigio de poder colonial. Lucas Alamán, líder de los conservadores mexicanos, dijo que los españoles europeos «no tenían más alternativa que sufrir los vaivenes de la política y las vicisitudes de los primeros gobiernos nacionales ${ }^{36}$. Pero la situación en España tampoco se presentaba muy boyante, las guerras de independencia americana casi llevaron a la bancarrota al comercio gaditano y la crisis económica asolaba las arcas españolas. El comerciante nestosano radicado en Veracruz, Antonio Gómez, resume en una de sus cartas

31 Carta de Francisco de Carranza a José de la Lama (del comercio de Veracruz), Cádiz, 17 de abril de 1820, FFC. FFC.

32 Carta de José Gutiérrez a Francisco de Carranza. Guadalajara, 16 de abril de 1819.

33 Carta de Francisco de Carranza a Bernabé Gutiérrez Higuera (de Madrid), Cádiz, 15 de diciembre de 1820 , FFC.

34 AGI, Indiferente, 2146, N. 96, 4 de febrero de 1821.

35 Carta de Manuel Sáenz de la Lastra a Francisco de Carranza, Lanestosa, 4 de junio de 1820 , FFC.

36 Alamán, 1975: 811. 
lo que sucedía en esos momentos: «Observamos que no llega ningún comerciante aquí a emplear como lo hacían por este tiempo anteriormente. Lo que prueba muchas cosas, tal como la abundancia de ropas en todo el reino pues en México están con $8 \%$ más baratas que aquí». Pues bien, en medio de este ambiente hostil e inestable, tenemos la primera noticia de Francisco Martínez Negrete en México. En la misma misiva anterior Gómez se sorprendía del valor y decisión de su paisano al llegar a Veracruz procedente de Guadalajara: «Martínez sobrino de Negrete $^{37}$ ha llegado aquí, y me parece (aunque nada me ha franqueado) que venía por consejo de Gutiérrez Valle, a una oferta de compañía que le hizo D. Manuel de Hoz». La profunda crisis que asoló al comercio veracruzano impidió que este negocio tuviera éxito, por lo que se vio obligado a regresar a Guadalajara con una carga que el mismo Valle le había facilitado. Aunque las innumerables partidas insurgentes y de asaltadores que infestaban el camino a México, no amedrentaron al joven Martínez Negrete, sí suscitó la preocupación de su tío el general Negrete cuando supo de su viaje, y así se lo expresó: «Dime a quién doy orden para que pague tu entierro en Veracruz». Para su paisano Antonio Gómez este joven «desde luego no vino con aprobación de nadie y se le echa de ver que tiene su granito de presunción poco fundada» ${ }^{38}$.

Martínez no regresó con las manos vacías del puerto jarocho, su paisano Carranza le había enviado desde Cádiz cuatro cajones de libros de distinta índole tales como de medicina (enfermedades lácteas, venérea, botánica), religiosos, literatura, manual de comerciantes y hasta poesía clásica. En conjunto se trataba de cerca de más 500 ejemplares por un valor de 1.374 pesos y cuatro reales ${ }^{39}$.

Durante la primera semana de febrero de 1821 marchó con esta carga hacia el noroccidente mexicano y tan pronto llegó a Aguascalientes escribió al destacado comerciante nestosano Francisco Cerro, a quien se dirige como pariente, para preguntarle si podía dejar el cajón de libros en su casa hasta que regresara a esa ciudad ${ }^{40}$. Todo indica que Martínez Negrete viajaba por

37 Pedro Celestino José Negrete y Falla nació en la parroquia de San Esteban, en el municipio de Carranza, perteneciente a las Encartaciones de Vizcaya, el 18 de mayo de 1777 (localidad a escaso $11 \mathrm{~km}$ de Lanestosa) Tras una brillante carrera militar se pronunció en Guadalajara el 16 de junio de 1820 a favor del Plan de Iguala. A partir de este momento este vizcaíno se convertirá en el peninsular más destacado de esta década al ser nombrado por el Congreso mexicano uno de los tres máximos mandatarios del «Poder Ejecutivo». FFC.

38 Carta de Antonio Gómez a Francisco de Carranza, Veracruz, 2 de febrero de 1821,

39 Ibidem. 4 de febrero de 1821.

40 Carta de Francisco Martínez Negrete a Francisco Cerro (del comercio de Guadalajara), Aguascalientes, 26 de abril de 1821, FFC. 
todo el noroccidente, el Bajío y la ciudad de México, tal y como sucedió en 1823 cuando acompañó desde Sonora hasta esta ciudad a la familia de Juan Francisco Iribarren que regresaba a Europa huyendo de la inestabilidad del país. Un año después Martínez Negrete contrajo nupcias en Cosalá con la criolla de origen vasco María Trinidad Roncal Batiz, sobrina de Iribarren ${ }^{41}$. En 1825 nació en Durango su primogénito, José María de Jesús siendo padrino por poderes su tío el general Pedro Celestino Negrete, quien se encontraba en la capital de la nación.

Sin duda la extrema inestabilidad política en México, acrecentada a partir de la declaración de guerra del gobierno independiente al español el 25 de febrero de 1823, anulará el flujo mercantil entre ambas naciones (que tan solo se efectuará de modo encubierto en buques de bandera extranjera) y la correspondencia entre ambos países en liza será muy complicada. Francisco Ortiz se quejaba de que las autoridades mexicanas interceptaran cualquier carta sospechosa que llegara o saliera del país: «Toda carta que vaya de Europa... tiene que ser abierta en tres estafetas» ${ }^{42}$.

Gracias a una carta de José Gutiérrez sabemos que estos años fueron extremadamente complicados para los negocios y las bancarrotas e impagos fueron moneda corriente, de hecho su paisano Bernardo Bringas, tras arruinarse pudo al menos vivir en casa de un coterráneo: «Lo recogió va para un año D. Vicente Pumarejo y están los dos en compañía de D. Francisco Cerro» ${ }^{43}$. Asimismo, Gutiérrez indicaba que: «El comercio de esta se halla fatal por las continuas introducciones de efectos y falta de numerario, pues los introductores por vender y los establecidos por no exponerse a sufrir el quebranto de vender a 8 lo que compran a $10 »^{44}$.

\section{EL RETORNO DE LOS NESTOSANOS: EL PRINCIPIO DE UN FINAL INEVITABLE}

Ya desde la segunda década del siglo XIX muchos españoles que intuyeron el fin del virreinato decidieron abandonar México y dar por finalizada en muchos casos toda una vida en tierras americanas, tal y como lo hicieron en

41 Carta de Francisco de Carranza a Juan Francisco Iribarren (Bayona), Cádiz 17 de junio de 1825, FFC. FFC.

42 Carta de Francisco Ortiz a Francisco de Carranza, Sevilla, 27 de diciembre de 1828, FFC.

43 Carta de José Gutiérrez a Francisco de Carranza, Guadalajara, 16 de mayo de 1826, FFC.

44 Carta de José Gutiérrez a Francisco de Carranza, Guadalajara, 16 de julio de 1826, 
1817 los comerciantes nestosanos en Guadalajara, Manuel Sainz de Rozas, Bernardo Bringas y Manuel Sainz de Lastra. Los españoles asentados en el noroccidente mexicano que decidieron regresar a la península lo pudieron hacer por dos vías, tal y como escribió Francisco Ortiz: «El hacerlo por Panamá si lo verifican no vienen muy seguros por los piratas que andan por esas aguas, por tierra a Veracruz sería mejor», aunque esta segunda opción no estaba exenta de los peligros de las partidas insurgentes ${ }^{45}$. Un año más tarde, otro comerciante nestosano, Rafael de Escorza Caballero tras pasar varios años en Guadalajara en casa de sus tíos, regresó a la península. Asimismo, Antonio Gómez aprovechó la coyuntura y tan pronto como pudo remitió a su corresponsal en Cádiz, Francisco de Carranza, una remesa de 2.000 pesos para que la mantuviera «sin emplearlo en cosa alguna [...] pues así lo exigen imperiosamente las circunstancias políticas en que se halla envuelto nuevamente este reino» ${ }^{46}$. Cinco meses después y antes de embarcarse rumbo a España se despedía de este modo: "Concluí mis asuntos de la manera que pude y no como quería; empezando a sacrificar intereses pues de otra manera sería víctima como otros muchos perdiendo el todo por la parte» ${ }^{47}$.

Aunque al declararse la Independencia, los españoles que decidieron regresar pudieron hacerlo con sus caudales, tal y como venía recogido en el artículo 15 de los Tratados de Córdoba ${ }^{48}$, la falta de numerario era tan importante en toda la nación que en muchas ocasiones debían sustituirlo por productos de gran demanda en los puertos europeos, ya que eran incapaces de cobrar sus deudas en plata. Así Antonio Gómez daba instrucciones de cómo se debía actuar al respecto: «[...] si no es fácil vender mis efectos a plata, lo hagas a cambio de granas ${ }^{49}$. Pocos días antes de proclamarse la independencia, embarcó con su familia en la fragata Veloz Mariana y tras 25 días de navegación arribó a La Habana para dirigirse finalmente a Cádiz ${ }^{50}$. En marzo de 1822 ya se encontraba en Sevilla en donde encontró una plaza poco activa FFC.

45 Carta de Francisco Ortiz a Francisco de Carranza, Pánuco, 29 de octubre de 1818, FFC.

46. Carta de Antonio Gómez a Francisco de Carranza, Veracruz, 08 de abril de 1821,

47 Carta de Antonio Gómez a Francisco de Carranza, La Habana, 14 de septiembre de 1821, FFC.

48 Díaz y Martini, 1977. Art. 15 de los Tratados de Córdoba: «[...] que no podrá negárseles, para salir del reino en el tiempo que se prefije, llevando o trayendo consigo sus familias y bienes; pero satisfaciendo a la salida por los últimos, los derechos de exportación establecidos o que se establecieren por quien pueda hacerlo».

49 Carta Antonio Gómez a Francisco de Carranza, La Habana, 30 de marzo de 1822, FFC.

50 Ibidem, 14 de septiembre de 1821, AFC. 
y de difícil inversión, por lo que decidió trasladarse a Madrid para tantear las posibilidades que ofrecía la capital del reino. El panorama no resultó de su agrado y decía quejumbroso: «Aquí [Madrid] ya me estoy aburriendo probablemente volveré a Sevilla: no se puede vivir donde hay un enjambre de parientes con chiquillos y otras gaitas: Más dinero se gasta en un mes que ahí en 3 y sobre todo no hay negocio de provecho al menos hasta ahora no lo descubro» ${ }^{51}$.

A su vez, Francisco Ortiz se embarcaba con su familia rumbo a Cádiz en la Veloz Mariana. Había contraído matrimonio en Pánuco con la criolla de ascendencia vasca Anacleta Batiz Vega (n. en Santa Úrsula, Cosalá, 1792), tía de Trinidad Roncal Batiz, esposa de Martínez Negrete. Gracias al esposamiento de María Rosa Batiz Vega con Juan Francisco Iribarren ${ }^{52}$ la red parenteral de Martínez Negrete se fue expandiendo. Los Iribarren abandonaron Durango y tras pasar unos años en Bayona, en 1829 se instalaron definitivamente en Sevilla.

Así mismo, algunos criollos decidieron abandonar México y viajar a la península. Un ejemplo significativo fue Juan Bautista Íñigo Ruiz, quien prefirió salir de su país y ser fiel a su rey. Íñigo había nacido en San Miguel de Horcasitas (Sonora) en 1787, hijo de los nestosanos Fernando Íñigo Ruiz y María Francisca de Monteagudo, importante hacendado y minero que tras dejar sus negocios en manos de su hermano Cornelio, se afincó en Burdeos en donde formó la destacada casa comercial Hijos de Íñigo Ezpeleta y Cía. En este puerto convivió con otros comerciantes procedentes de Guadalajara como Ventura García Sancho, Domingo de Ibarrondo y Antonio de Ibarrondo, con los que mantuvo una estrecha relación personal y comercial. En 1832 fue nombrado por Fernando VII, Caballero Supernumerario de la Real y Distinguida Orden de Carlos III ${ }^{53}$, en parte como muestra de agradecimiento por su ofrecimiento por costear un ejército reconquistador de 8.000 hombres armados y también por lograr en 1830, y por un periodo de diez años, el control de la explotación y suministro al Estado de las minas de Almadén ${ }^{54}$.

El flujo de emigrados que recalaron principalmente en Cádiz disminuyó hasta casi desaparecer prácticamente a finales de 1824. Durante los tres años

51 Carta de Carta de Antonio Gómez a Francisco de Carranza, Madrid, 31 de mayo de 1822, FFC.

52 Juan Francisco Iribarren San Martín nació en Ostiz (Navarra) el 4 de mayo de 1768. En 1789 a bordo del buque El Mentor llegó a la Nueva España. Su destino fue Durango en la casa de comercio de su tío Benito Iriarte.

53 Caballero Supernumerario de la Real y Distinguida Orden de Carlos III por Decreto de 25 de junio de 1832, Exp.2146.

54 Delgado, (1950-53), Vol. I, 445 y Apéndice, doc. XXVIII. AGI, Indiferente General, 1.564 . 
siguientes los españoles que decidieron dejar México lo hicieron principalmente en barcos de bandera francesa e inglesa con destino a Burdeos o Portsmouth, ciudades en donde podrían seguir con sus negocios. Aunque, como decía Carranza a un paisano del comercio de Madrid, «los americanos que han venido a la península corriendo de un punto a otro como pájaros fuera de la jaula y espantados, e irresolutos en fijar asiento» ${ }^{55}$.

Los rumores de preparativos de reconquista y la radical propaganda de la masonería de la logia yorkina, provocó la última oleada de retornados antes de que se dictasen las leyes de expulsión de españoles en los años 1827 y 1829 . La decisión del Congreso mexicano de promulgar estas leyes obligó a los peninsulares a reordenar sus vidas y negocios. Para poder salvar la mayor cantidad de bienes otorgaron poderes a familiares y testaferros mexicanos para que protegiesen sus intereses y vendieran con celeridad lo que se pudiera, y con ello afrontar el incierto exilio. Pero, recuperar el capital invertido en el comercio resultaba complicado, teniendo en cuenta que el dinero estaba en continuo movimiento.

El drama del destierro de los españoles que causaron estas leyes ha sido estudiado en profundidad por Ruiz de Gordejuela. De su monografía La tragedia del exilio: Los españoles expulsados de México y su destino incierto (1821-1836) ${ }^{56}$, extraemos que más de 3000 expulsados partieron rumbo a los puertos de Nueva Orleans y Burdeos y que otros varios cientos lo hicieron a La Habana. El puerto luisiano fue el destino inmediato y casi obligado de al menos la mitad de los afectados por las leyes de expulsión, con cerca de 1.500 españoles registrados a su entrada por las autoridades portuarias norteamericanas. Para desgracia de los expulsados, entre los meses de febrero de 1828 y 1829 se produjo un brote epidémico de fiebre amarilla que provocó la muerte a cientos de afectados por estas medidas antiespañolas en Veracruz y Nueva Orleans. Al menos otros 1.500 expulsos llegaron al puerto de Burdeos entre 1828 y 1830 procedentes de México, Cuba y en menor medida de los Estados Unidos de América. A partir de 1830 los que aún permanecían en Nueva Orleans esperaron el momento oportuno para burlar a las autoridades mexicanas y volver discretamente a México, mientras los emigrados que habían recalado en Francia terminaron por cruzar la frontera y regresar a España. Aunque los que no lo hicieron no fue tanto por temor a las medidas represoras del régimen de Fernando VII, sino más bien, por los altos impuestos que el gobierno español impuso a las remesas de plata que llegaban del extranjero.

En mayo de 1828 Carranza comentaba a su primo Francisco Ortiz que: «Estamos en duda, si los Nestosanos de Guadalajara habían salido atravesan-

55 Carta de Francisco de Carraza a Feliciano del Arco, Cádiz, 9 de junio de 1820, FFC.

56 Ruiz de Gordejuela Urquijo, 2006. 
do el reino para embarcarse en Veracruz o lo hacían por San Blas en una fragata de Íñigo, de Burdeos, que allí estaba, y venirse por el cabo de Hornos» ${ }^{57}$. No cabe duda de que en la península se esperaba su llegada: «No hay noticias de que los paisanos de Guadalajara en Nueva España, hayan llegado a ningún puerto de Europa ${ }^{58}$. José Gutiérrez y Cipriano Mier y Cerro que se hallaban en Guadalajara regresaron a sus pueblos natales y «se encuentran ahora apeteciendo colocación en alguna parte según me han escrito; les he contestado que por acá no es posible». Mientras, el rumor de que otros nestosanos tomaran la misma decisión llegó a oídos de sus paisanos en la península: "Caballero, Murua y Cerro han escrito con fecha 24 de enero, que esperaban allí la fragata de Iñigo, de Burdeos y una corbeta de guerra inglesa; tal vez vengan en alguna de ellas» ${ }^{59}$.

También en junio de 1828 llegaba a París, vía Londres, Juan Manuel Lama, tras abandonar sus negocios en México y con el objeto de arreglar algunos asuntos y continuar viaje a $\mathrm{Cádiz}^{60}$. En una de sus cartas escribía sobre los últimos acontecimientos de México, entre los que destacaba la crítica situación del comercio en la capital y en Veracruz y la inseguridad entre ambos puntos. Asimismo, informaba que «el pabellón inglés había sido arrastrado» y que «tres mil pasaportes se habían expedido para europeos hasta el 2 de enero». También informaba que la incertidumbre ante la pérdida de las propiedades de los españoles en México aumentó aún más cuando el ministro de Hacienda José Ignacio Esteva propuso la confiscación total de los bienes de los «españoles salidos y estantes» y así cubrir el déficit de la nueva nación. Lama advertía que la expulsión total de españoles era inminente «pues en esto influían todos los extranjeros principalmente los angloamericanos, que desde un principio nos han corrido bien la diligencia con el objeto de aprovecharse de nuestros despojos» ${ }^{61}$.

Respecto a Martínez Negrete sus paisanos de la península ya conocían en octubre de 1828 que había abandonado México, aunque sin precisar su ubicación exacta, y Lama escribía al respecto que «si Martínez Negrete pasa a Burdeos, comunicará noticia del país que ha dejado» ${ }^{62}$.

Desde la ciudad vascofrancesa de Bayona, Francisco José Iribarren comentaba a Carranza que «Martínez y Murua iban a despedirse de su familia para

57 Carta de Francisco de Carranza a Francisco Ortiz, Cádiz, 2 de mayo de 1827, FFC.

58 Ibidem. Cádiz, 20 de mayo de 1827.

59 Ibidem. Cádiz, 30 de mayo de 1828.

60 Carta de Juan Manuel de Lama a Francisco de Carranza, París, 22 de enero de 1829, FFC. En octubre de este mismo año fallecía sin testar en París.

61 Ibidem. París, 5 de marzo de 1829.

62 Ibidem. Cádiz, 14 de octubre de 1828. 
retirarse a los Estados Unidos o Burdeos por causa de las convulsiones de México con que considera que bueno andará» ${ }^{63}$. Martínez Negrete llegó el 8 de diciembre de 1828 a Liverpool procedente de Nueva York y tras una breve estancia en Londres, el 6 de enero del año siguiente se dirigió a París. «Dicho amigo dejó su familia en aquel punto [Nueva York]... El expresado lleva intención de pasar a la Península y su permanencia será hasta septiembre $\mathrm{u}$ octubre que piensa regresar a Nueva España» ${ }^{64}$. Pues bien, se conoce que la incertidumbre, no solo política sino también económica hizo dudar sobre las intenciones de este porque en marzo de este año su coterráneo Francisco Ortiz escribía que «Alcober [banquero español de París] dice que Martínez Negrete ha escrito a su familia se venga a Gibraltar y que en el mes próximo [abril] partía el mismo Negrete para Madrid, de donde se dirigirá a recibirla para trasladarse allí» ${ }^{65}$. Finalmente, el 2 de mayo llegó a la capital española en espera de que su esposa Trinidad Roncal y sus tres hijos ${ }^{66}$, la hermana de esta, Josefa y su marido Félix Romero llegaran a Gibraltar. Mientras estos abandonaban Cádiz, Carranza se encargó de facilitar un pasaje de vuelta a Nueva York en la fragata Fabius a una criada irlandesa de nombre Urri que había sido contratada para amamantar al hijo pequeño de Francisco Martínez Negrete durante la travesía. El 9 de junio viajaron a Jerez de la Frontera a bordo del vapor Coriano para visitar a la familia de Romero y pocos días después fijaron su residencia en Sevilla, en la casa de María Anacleta Batiz (tía de las hermanas Trinidad y Josefa Roncal).

Por fin la familia se reencontró en Madrid y así cuidar a su hijo menor, que en palabras de Martínez Negrete «se ha hallado al borde de la muerte de resultas del destete y dentición, pero actualmente se ha logrado que vuelva a tomar el pecho con una montañesa robusta que lo cría bien». Poco tiempo permanecieron en la capital, puesto que para el 19 de agosto los matrimonios Martínez Negrete y Romero viajaron a Lanestosa. Pero antes de asentarse en su pueblo natal, permanecieron en Bilbao dos semanas, tiempo que aprovecharon para visitar a amigos y parientes ${ }^{67}$. Romero marchó a París y en julio del siguiente año se embarcó rumbo a Nueva York y La Habana. En noviembre de 1829 desembarcaba en Cádiz procedente de los Estados Unidos el

\footnotetext{
63 Ibidem. Cádiz, 29 de octubre de 1828

${ }^{64}$ Carta de Felipe González a Francisco de Carranza, Londres, 7 de enero de 1829, FFC.

65 Carta de Francisco Ortiz a Francisco de Carranza, Sevilla, 28 de marzo de 1829, FFC.

66 Los tres hijos son: José María de Jesús, (n. en Durango en 1824), María Trinidad Lorenza (n. en Durango en 1825) y Francisco Félix (n. Cosalá en 1828).

${ }^{67}$ Carta de Félix Romero a Francisco de Carranza, Lanestosa, 24 de septiembre de 1829, FFC.
} 
nestosano, Miguel Murua, quien viajó solo desde Durango, mientras su esposa Encarna (otra hermana Roncal Batiz), junto a sus dos hijos pequeños no llegarían hasta junio del siguiente año.

El general Negrete también se vio obligado a abandonar su país adoptivo y cuando recaló en Nueva York, visitó a su sobrina Trinidad Roncal el 4 de mayo para que tan pronto pudiera su esposo le entregase una carta orden de ochenta onzas de oro a su deudor Nicolás de la Vega, quien ocupaba en ese momento el cargo de veedor del departamento de $\mathrm{Cádiz}^{68}$. Esta deuda fue contraída veinte años antes en Veracruz y ante la extrema necesidad en el que se hallaba Negrete, sin recursos para subsistir, le instó para que hiciese efectivo el pago a «mi sobrino D. Francisco Martínez Negrete para que este me auxilie lo más pronto posible en mi grave necesidad» ${ }^{69}$.

Martínez Negrete desde Lanestosa se quejaba a Carranza que «aquí me tiene usted retirado con toda mi familia pasando una vida monótona y vegetadora esperando los resultados de la expedición a México para trasladarnos allá si fueren felices» ${ }^{70}$. La incertidumbre era tal que Martínez Negrete no sabía ni cómo actuar ni a dónde ir. Su preocupación por los resultados de la expedición de reconquista de México bajo las órdenes del general Isidro Barradas determinaría su rápido regreso, pero por desgracia para los intereses de los españoles de México, la expedición fue un rotundo fracaso ${ }^{71}$. Pero antes de que fuera público este nefasto desenlace, escribía de nuevo a Carranza para que le informara «si está próximo a salir para La Habana algún barco, qué pasaje se paga y si dan ahí mismo pasaporte para dicho punto» en previsión de que su regreso a México pudiera ser inmediato ${ }^{72}$. Ante el desastre reconquistador pensó en establecerse en Cádiz «porque agrada a mi familia y espero me dé su opinión y que cosa podremos emprender con aprovechamiento, sobre el caso de tirarnos a lo que se presente, pues ya rabiamos por trabajar». El invierno en Lanestosa es frío y húmedo y así se quejaba Martínez Negrete: «Nada gusta a mi familia ni este país ni su riguroso temperamento», cir-

68 Carta de Francisco Martínez Negrete a Francisco de Carranza, Madrid, 21 de julio de 1829 , FFC.

69 Carta de Pedro Celestino Negrete a Nicolás Infanzón de la Vega, Nueva York, 4 de mayo de 1829, FFC. Pedro Celestino Negrete llegó a El Havre en enero de 1832 procedente de Nueva York con la intención de trasladarse a Burdeos.

70 Carta de Francisco Martínez Negrete a Francisco de Carranza, Lanestosa, 25 de septiembre de 1829 , FFC.

71 Ruiz de Gordejuela Urquijo, 2011b. Para conocer en profundidad este hecho consultar esta obra.

72 Carta de Francisco Martínez Negrete a Francisco de Carranza, Lanestosa, 27 de noviembre de 1829 , FFC. 
cunstancias que afectaron a la salud de su hija quien falleció con tan solo cuatro años ${ }^{73}$. Durante esta estancia fue elegido alcalde, distinción que no fue de su agrado: «Yo también me hallo aburrido en la ociosidad y por otro lado mortificado con tanto chismes y enredos que versan en este juzgado me ha nombrado alcalde sin pensarlo ni desearlo, circunstancia que me impele a salir cuanto antes». Estas circunstancias le animaron a ponerse «en movimiento y girar los pocos intereses que quedan en cualquiera cosa porque todavía estoy en buena edad para seguir mis trabajos, con pocas necesidades y acostumbrado a una vida económica, asidua y arreglada». Como señalábamos en líneas anteriores, el puerto de Cádiz se presentaba como la opción más sugerente y por ello se interesó por conocer cuánto necesitaría «para mantener una casa con nueve de familia, económicamente, pero sin carecer de lo necesario para vivir regularmente alquiler de casa etc.» $\rangle^{74}$. La valoración que le hizo Carranza no fue nada optimista al considerar que el gasto anual no bajaría de 2500 a 3000 pesos fuertes ${ }^{75}$. Finalmente, Martínez Negrete desechó la idea de asentarse en este puerto, y en septiembre se trasladó solo a París para arreglar ciertos asuntos con el banquero Mariano Alcober. A continuación, viajó a Burdeos con el propósito de embarcarse rumbo a México, pero antes, el 10 de mayo fallecieron sus gemelos recién nacidos, Pedro José y José Lorenzo. Un condiscípulo suyo, Felipe González escribía que: «Negrete está preparando su memoria para Mazatlán y Tampico. Por el primer punto piensa ir él y por el segundo trata de mandar el resto de la familia. Me ofrece con arrogancia que cuente yo si pasase a Durango que me proporcionará un regular establecimiento ${ }^{76}$. Mientras, su cuñado y socio, Miguel Murua, tras pasar unos días en Sevilla viajó a Burdeos para acompañarle en su viaje por el cabo de Hornos hasta Tepic. Cuando Martínez Negrete se hallaba en Francia, su mujer enfermó en Bilbao a mediados de diciembre. Este y Murua regresaron a esta ciudad antes de que falleciera finalmente el 12 de marzo de 1831. A su vez su cuñada Josefa, y esposa de Félix Romero, murió en Bayona cinco meses después. Las desgracias no vinieron solas, y en Sevilla perdía la vida el tío de las anteriores, Francisco Ortiz (primo carnal de Francisco de Carran-

73 Carta de Francisco Martínez Negrete a Francisco de Carranza, Lanestosa, 18 de diciembre de 1829, FFC.

74 Carta de Francisco Martínez Negrete a Francisco de Carranza, Lanestosa, 8 de febrero de 1830 , FFC. La misiva hace referencia a nueve miembros que compone la familia, las dos hermanas Roncal, sus maridos y los dos niños de Martínez Negrete.

75 Carta de Francisco de Carranza a Francisco Martínez Negrete, Cádiz, 23 de febrero de 1830 , FFC. FCC.

76 Carta de Felipe González a Francisco de Carranza, Londres, 8 de octubre de 1830, 
za). Su viuda confió en sus sobrinos Martínez y Murua para que se encargaran de todos los negocios de su marido en México. Una de las dificultades que padecieron los expulsos fue el cobro de los bienes que se vieron obligados a abandonar. Diez años después de su marcha de México, Anacleta Batiz, reclamaba 1.500 pesos por dos barras de plata que estaban en manos de su hermano Cornelio residente en el Rosario de Cosalá. Gracias a Juan Manuel Caballero, quien delegó en su socio Ramón Murua, remitió los pesos a la casa Aguirresolarte y Murrieta de Burdeos. A pesar de todas las gestiones, un año después la viuda seguía sin cobrar el dinero.

Aunque no disponemos de muchas noticias de Martínez Negrete durante el bienio 1832-1833, al menos sabemos que en diciembre de 1832 se encontraba en Burdeos y que durante la primera mitad del año siguiente viajó a España. Juan Abajas supo que Martínez Negrete tras regresar de España se encontraba «habilitándose para que su buque que ha fletado salga en todo julio para San Blas»y su desconfianza en los comerciantes bordeleses era patente, ya que según su opinión «a nadie se ha consignado ni ocupa más que a mí [Abajas]. Su desconfianza y economía no se lo permite y además que sin duda está persuadido que nadie sino yo le ha de servir sin intereses pues no espero recibir ninguna $\rangle^{77}$. Los tres concuñados habían fundado en la ciudad de México la compañía comercial Martínez, Murua y Romero y cada uno se ocupaba de espacios y negocios distintos. Así, el primero se estableció en Burdeos, Murua viajaba por toda Europa y llevaba los negocios desde ciudad de México y el tercero residía en Durango en donde tenía «tienda abierta» ${ }^{78}$. En una carta fechada en abril de 1834 Carranza pidió a José Zarragoitia, del comercio de Durango, que «sírvase vm. de dar mis afectos al amigo D. Félix Romero y a Negrete si apareciese por esa, pues que Murua sí que está de fijo en México ${ }^{79}$. Todo apunta a que Martínez Negrete regresó a la República Mexicana durante los primeros meses de 1834. Un año más tarde, el 30 de agosto, contrajo nupcias en el Sagrario Metropolitano de la catedral de Guadalajara con su sobrina en segunda línea, Josefa Alba Ortiz de Rozas ${ }^{80}$. Su padrino no fue otro que su paisano Juan Manuel Caballero. En el acta matrimonial se puede leer que Francisco Martínez Negrete salió de Lanestosa «hace dieciocho años y habiendo residido en Francia dos años, en Inglaterra cuatro

77 Carta de Juan de Abajas a Francisco de Carranza, Burdeos, 5 de junio de 1833, FFC. FFC.

78 Carta de José Zarragoitia a Francisco de Carranza, Durango, 28 de octubre de 1833,

79 Carta de Francisco de Carranza a José Zarragoitia, Cádiz, 10 de abril de 1834, FFC.

80 Carta de José de Zarragoitia a Francisco de Carranza, Durango, 14 de octubre de 1836, FFC. 
meses, en los Estados Unidos del Norte, y en distintas partes de nuestra República; se avecindó en esta capital». Lo que más llama la atención es que omite deliberadamente su estancia en España, ante el temor a que le pudieran aplicar la ley por la que se confiscaba todos los bienes a los expulsados que pasasen a territorio español.

De todo lo que les sucedió a los dos hijos de Martínez Negrete, lo desconocemos, aunque podemos confirmar que el 28 de agosto de 1838 vivían con sus tíos Lorenza Martínez Negrete y José Sainz de la Lastra en la calle Cosme de Médicis de Madrid. Lorenzo, el hijo pequeño, fallecería a lo largo de este año.

Mientras Murua compraba mercancías para la compañía de los tres cuñados en Burdeos, Madrid, Génova y Barcelona, Martínez Negrete estrechaba amistad con Juan Manuel Caballero en Guadalajara quien le confirió su confianza y amistad. De hecho, en noviembre de 1835 le nombró primer albacea $\mathrm{y}$ tenedor de bienes de su testamento con amplios poderes (lo que le otorgaba potestad para tomar decisiones) junto a los comerciantes Benito Cerro, Miguel Murua, José Miguel Pacheco, Manuel Ruiz Gutiérrez y José Palomar ${ }^{81}$.

Los jóvenes nestosanos no esperaron a que las relaciones diplomáticas entre España y México se resolvieran, para viajar a Guadalajara tal y como lo hicieran años antes sus paisanos. De hecho, Francisco María Ortiz y González, quien se había iniciado en el comercio de Madrid se encontraba en Burdeos, tal y como apuntaba su tío y paisano Felipe González «con la mira de que pase a servir en clase de dependiente de mi condiscípulo Francisco Martínez Negrete de Guadalajara, República de México, por un buque a doblar el cabo de Hornos que despachan en Burdeos en breve por cuenta de aquel mi otro condiscípulo Miguel Murua». Su tío se encargó de que viajara «de segundo sobrecargo en el buque y por supuesto libre de pasaje» ${ }^{82}$.

Finalmente, el joven se embarcó el 24 de septiembre en el barco inglés Lord Eldon con destino San Blas. Su tío Juan bajas decía de él que «es excelente joven bastante instruido y ha cautivado a Murua, con su disposición y servicios en esta, de suerte que este amigo nos ha asegurado de su suerte». Para salvar la prohibición de entrada a los españoles en México, Abajas le proporcionó «pasaporte que acredita ser nativo de Buenos Aires». Esta fue sin

81 Olveda Legaspi, 2003: 205. Testamento realizado por Juan Manuel Caballero ante el notario Miguel María de Robles, 27/11/1835, ff. 187v-190. AHIPJ (Archivo Histórico de Protocolos de Jalisco)

Aunque no exista documento alguno en el que se haga referencia a la comisión que debiera recibir el albacea encargado de su administración, en México esta podría llegar al 20 \%. FFC.

${ }^{82}$ Carta de Felipe González a Francisco de Carranza, Londres, 15 de agosto de 1835, 
duda una práctica extendida ya que muchos jóvenes españoles se hicieron con documentos en los que constaba su condición de americano o francés ${ }^{83}$. El volumen de la expedición se compuso de «buenos renglones y de valor en Europa de 900.000 francos [45.000 pesos]» ${ }^{84}$, ninguna bagatela, y que viene a demostrar que la compañía formada por los tres cuñados era de cierta importancia y máxime para una economía como la tapatía que sufría una profunda crisis económica.

El citado joven, tras asentarse en Guadalajara, recibió el apoyo de su protector Martínez Negrete quien no solo aprobó su matrimonio con su cuñada Antonia Alba Ortiz de Rozas «que es pobre, pero de las más decente de aquel país» en enero de 1839 si no que también le hizo partícipe de sus negocios ${ }^{85}$.

Tras el fallecimiento de Juan Manuel Caballero, el 20 de marzo de 1837, Francisco Martínez Negrete fue acusado de quedarse con sus bienes por parte de los sobrinos de la península despojados de la herencia. La voluntad de Juan Manuel Caballero se cumplió y toda su fortuna, cercana al millón de pesos, fueron donados a la beneficencia. No cabe duda, de que el anciano vio en su paisano y pariente un ejemplo de hombre religioso, trabajador, recto y sagaz comerciante. La historiografía ha aceptado la tesis defendida por los familiares excluidos de la testamentaría en la que se desacreditaba a Martínez Negrete, presentándole como oportunista y manipulador, pero hay que recordar que su pasado le avalaba como un brillante y perseverante hombre de negocios.

El primero en manifestar su enfado fue Antonio Gómez, sobrino de Caba1lero, quien escribió al general Pedro Celestino Negrete, para que intercediera ante su sobrino Martínez Negrete para que le facilitase una copia literal de la disposición testamentaria. Asimismo, se quejaba de que la familia residente en España no hubiera sido informada del deceso. Pero evidentemente, este hecho no era el asunto que tanto le disgustaba a Antonio Gómez y a sus hermanos, y criticaba que: «Recientemente, se hace correr por aquí una relación mal dirigida de las mandas que se suponen hechas por el finado, en la cual hay inexactitudes y parcialidades extrañas por cierto». Los hermanos Gómez achacaban este comportamiento a que «se observan en ella también una especie de acrimonia brusca separando o excluyendo a ciertos individuos de la familia so color de que no lo necesitan hasta tal punto que más parece

83. Registro de pasaportes de salida (1828-1836), 4M 713-4M716 y R 90. Archivo Departamental de la Gironda, Burdeos FFC.

84 Carta de Juan Abajas a Francisco de Carranza, Burdeos, 26 de septiembre de 1836,

85 Carta de Juan Abajas a Francisco de Carranza, Burdeos, 12 de mayo de 1838, FFC. 
un castigo debido a un crimen, pasto de la más negra desafección, que un olvido natural» ${ }^{86}$.

Gracias a la correspondencia entre el referido Gómez y Carranza sabemos que Martínez Negrete, como primer albacea, remitió a su tío el general Negrete 19.000 pesos para que en virtud de los informes elaborados por los nestosanos Lastra y Gutiérrez los distribuyera entre sus parientes pobres. Parte de este legado recayó en la parte femenina de la familia, que era la más desprotegida. «Entre los agraciados se cuentan cuatro de mis hermanas y la mujer de Colina que recibió más de 20.000 duros del finado su hermano Juan Manuel [de la Lama]». Asimismo, se sintió profundamente agraviado y así lo expresaba: «Por supuesto nada para los tres hermanos míos, ni para mí por considerarlos los legisladores. Han hecho en Lanestosa un entierro en el que figuraban los parientes de Martínez y nada de los Caballero. Nos han cogido una ojeriza terrible». Pero la responsabilidad no se la atribuye al difunto Juan Manuel Caballero sino a que todo es parte de una estratagema argüida dos años antes de su muerte por Martínez Negrete: «A Valerio, Dionisio, Teresa y Mariquita [Gómez Caballero] les dan mil duros en cada uno, y más de 500 duros para dote de sus hijas por ser pobres, y a Felipe Murua le dan 500 duros. Sépase que su hermano se encuentra en Indias ocupando la casa mortuoria [se refiere a su casa comercial en Guadalajara]. A Cayetano Fernández el de Veracruz otros mil duros ${ }^{87}$. No cabe duda de que el enojo fue mayúsculo y en 1839 un sobrino del finado procedente de las Montañas de Santander, Pedro María Moncalián, viajó a Guadalajara para demandar a su primer albacea en representación de los desheredados de la península. Martínez Negrete, ante las continuas acusaciones de apropiación de bienes y del esfuerzo que conllevaba ejecutar la testamentaría, renunció a su compromiso en 1844 y traspasó el albaceazgo a Miguel Murua. Finalmente podemos decir que este embrollo judicial no llegó a ninguna parte, y tras 31 años de litigios, Martínez Negrete quedaba exonerado de todas las acusaciones vertidas ${ }^{88}$.

Francisco Martínez Negrete falleció en Guadalajara en 1874, tras convertirse en uno de los más importantes y poderosos hombres de negocios del Jalisco decimonónico ${ }^{89}$. A partir de este momento serían sus hijos y yernos los que lucharían por perpetuar su legado. FFC.

86 Carta de Antonio Gómez a Pedro Celestino Negrete, Madrid, 14 de mayo de 1838,

87 Carta de Antonio Gómez a Francisco de Carranza, Madrid, 12 de junio de 1838, FFC.

88 Moncalián, 1884. Esta obra se puede consultar en la Biblioteca Pública del Estado de Jalisco "Juan José Arreola".

89 Olveda Legaspi, 1991. Lizama, 2013. 
Pero para entonces, los nestosanos, sin familiares y paisanos en Guadalajara que les permitieran ser miembros de un grupo privilegiado, tuvieron que buscar otros destinos en América (Guatemala, Puerto Rico y Cuba) en donde «hacer las américas», aunque nunca volvería a ser tal y como lo expreso el alcalde de Lanestosa, en referencia a sus paisanos en Guadalajara que: «Estos son los dueños de aquella ciudad».

\section{BiBLIOGRAFÍA}

Alamán, Lucas, Historia de México desde los primeros movimientos que prepararon su independencia en el año de 1808 hasta la época presente, 5 vols. México, Jus, 1975.

Brading, David A., Mineros y comerciantes en el México borbónico (1763-1810), México, FCE, 1975.

Castañeda, Carmen, "Los vascos, integrantes de la élite en Guadalajara, finales del siglo XVIII)", Carmen Castañeda (coord.), Círculos de Poder en la Nueva España, México, Ciesas-Porrúa, 1998: 167-182.

Delgado, Jaime, España y México en el siglo XIX, 3 vols., Madrid, CSIC, 1950-1953.

Díaz, Luis Miguel y Martini, Jaime G., Relaciones Diplomáticas México-España (1821-1977), México, Porrúa, 1977.

Garritz, Amaya, Los vascos en las regiones de México, siglos XVI-XX, vol. II, México, UNAM, 1996.

Ibarra, Antonio, "Mercado, elite e institución: el Consulado de comercio de Guadalajara y el control corporativo de las importaciones en el mercado interno novohispano", Bernd Hausberger y Antonio Ibarra (eds.), Comercio y poder en América Colonial. Los consulados de comerciantes, siglos XVII-XIX, Madrid, Iberoamericana-Vervuert-Instituto Mora, 2003, 145-170.

Jiménez Pelayo, Águeda, Élites y Poder. México y España, siglos XVI al XX, Guadalajara, Universidad de Guadalajara, 2003.

Kizca, John E., Empresarios coloniales, familias y negocios en la ciudad de México durante los Borbones, México, FCE, 1986.

Kicza, John E., "El papel de la familia en la organización empresarial en la Nueva España", Familia y poder en Nueva España. Memoria del tercer simposio de Historia de las Mentalidades, Seminario de Historia de las mentalidades, Colección Científica Serie Historia, México, INAH, 1991.

Labayru, Jaime, Historia General de Vizcaya, Tomo II, Madrid, Librería de Victoriano Suárez, 1885. 
Lancaster-Jones, Ricardo, "Guadalajara y Don Juan Manuel”, Historia Mexicana, 1, 4 (México, abril-junio de 1952): 655-662.

Lizama Silva, Gladys, "Francisco Martínez Negrete: un comerciante y empresario de la élite tapatía, 1824-1874", Águeda Jiménez Pelayo (ed.), Élites y Poder. México y España, siglos XVI al XX, Guadalajara, Universidad de Guadalajara, 2003.

Lizama Silva, Gladys, Llamarse Martínez Negrete. Familias, redes y economía en Guadalajara, México, siglo XIX, Zamora, El Colegio de Michoacán, 2013.

López Gil, Manuel, Valle de Carranza. Hijos ilustres de Carranza, Bilbao, 1975.

Madoz, Pascual, Diccionario geográfico-estadístico-histórico de España y sus posesiones de Ultramar, 16 v., Madrid, Imp. Del Diccionario,1848-1850.

Moncalián, Miguel, Historia de la Testamentaría de D. Juan Manuel Caballero, Guadalajara, Tip. de Las clases productoras, 1884.

Olveda Legaspi, Jaime, La Oligarquía de Guadalajara. De las reformas borbónicas a la reforma liberal, México, Consejo Nacional para la Cultura y las Artes, 1991.

Olveda Legaspi, Jaime, “Juan Manuel Caballero. Integración y desintegración de una fortuna" Garritz, Amaya, Los vascos en las regiones de México, siglos XVI-XX, vol. II, México, UNAM, 1996.

Olveda Legaspi, Jaime, En busca de la fortuna. Los vascos en la región de Guadalajara, Guadalajara, El Colegio de Jalisco-RSBAP, 2003.

Ruiz de Gordejuela Urquijo, Jesús, La tragedia del exilio: Los españoles expulsados de México y su destino incierto (1821-1836), Sevilla, Universidad de Sevilla-CSIC-Diputación Provincial de Sevilla, 2006.

Ruiz de Gordejuela Urquijo, Jesús, Vivir y morir en México. Vida cotidiana en el epistolario de los españoles vasconavarros, 1750-1900, Vitoria-Gasteiz, Nuevos Aires-Gobierno Vasco, 2011a.

Ruiz de Gordejuela Urquijo, Jesús, Barradas, el último conquistador español. La invasión de México 1829, México, Secretaría de Educación Pública del Gobierno de México, Instituto Nacional de Estudios Históricos de las Revoluciones de México (INEHRM), $2011 \mathrm{~b}$.

Ruiz de Gordejuela Urquijo, Jesús, Los vasconavarros en México, México, LID, 2013.

Fecha de recepción: 7 de febrero de 2019.

Fecha de envío de las modificaciones: 6 de mayo de 2019.

Fecha de aceptación: 12 de junio de 2019. 


\section{Natives of Lanestosa in Guadalajara. Triumph and decline of an elite group, 1780-1836}

This article aims to explain how, during the last quarter of the eighteenth century, people native to Lanestosa (Vizcaya) were able to establish an important network of fellow townsfolk in the Novohispanic city of Guadalajara. They became a privileged group, attaining economic and social success, as personified in the figure of Juan Manuel Caballero. The instability caused by the Insurgency undermined their prominent role, leading many to return to Spain to resume their lives. We have drawn on the unpublished correspondence of Francisco de Carranza, a merchant settled in Cadiz, which sheds unprecedented light on aspects of the life of Francisco Martinez Negrete before he became a key figure in the northwest Mexico of the nineteenth century.

KeY words: emigration; Basques; Lanestosa; Mexico; Juan Manuel Caballero; Francisco Martinez Negrete; expulsion of Spaniards. 